\title{
SEISMIC DESIGN OF SOUTH BRIGHTON BRIDGE .
}

\section{A DECISION AGAINST MECHANICAL ENERGY DISSIPATORS}

\author{
M.J.N. Priestley* and M.J. Stockwell**
}

SUMMARY

The seismic design of a proposed Christchurch bridge is discussed. Initial design was based on supporting the superstructure on elastomeric bearing pads and steel-cantilever dampers. Dynamic analyses showed that the dampers were relatively ineffective, and that the seismic response was dictated by the characteristics of the bearing pads. Final design, based on a conventional ductile approach was found to be more economical without significant increase to seismic risk. It is shown that the decision to opt for a design incorporating mechanical energy dissipators as opposed to a monolithic pier/superstructure design will not necessarily result in a reduction in seismic response.

\section{INTRODUCTION}

\section{1 Location}

The South Brighton Bridge has been designed to replace an existing old timber bridge built in 1926, situated just upstream from the junction of the Avon river with the Christchurch Estuary. Replacement is necessary due to the narrow bridge width and unsuitable sighting with respect to adjacent road realignment.

\subsection{Structural system}

For a satisfactory balance between superstructure depth and substructure works a three span solution was chosen, incorporating 22m MWD prestressed I beams and a cast-in-situ concrete deck. The superstructure will be continuous over the internal piers with separation achieved at abutments by deck joints. Elastomeric bearings support the superstructure at abutments and internal hammerheads, and were chosen for their maintenance-free characteristics in the aggressive salt water environment. Fig. 1 shows general structural details.

Seismic forces will be resisted in each direction by single-column octagonal piers acting as vertical cantilevers from rigid pilecaps. These are supported by raking piles founded in dense sand. Other salient features of the seismic design include knock-off tops and linkage bolts at abutments, with superstructure displacement limiters (earthquake stops) at pier hammerheads. Similar details have been fully described elsewhere (I).

\subsection{Seismic Design Fhilosophy}

Current New Zealand bridge design philosophy (2) suggests equivalent static force analysis and design for ductility. This can be achieved either by plastic hinging of the piers or by the incorporation of energy dissipating devices between the

* Reader in Civil Engineering, University of Canterbury. Christchurch.

* Structural Design Engineer, Christchurch City Council. superstructure and supports.

\subsection{Energy Dissipators}

Mechanical energy dissipators have been successfully developed and tested by the Physics and Engineering Laboratory, N.Z. Department of Scientific and Industrial Research (P.E.L.) (3) On the basis of a review by $B$ lakeley $(4)$ into aspects of the incorporation of these devices in bridges, it was elected to examine the use of cylindrical 'vertical cantilever' dissipators between the superstructure and pier hammerhead to reduce structural ductility requirements under seismic attack. The omnidirectional characteristics of these devices made them appropriate for combination with the other omnidirection components in the seismic force-transfer system (elastomeric bearings and octagonal piers). It was anticipated that the dissipators would greatly reduce pier hinging, and hopefully eliminate the need for ductile pier design. Resulting benefits would be possible economics in pier reinforcement, and limitation of structural damage to the easily replaceable dissipators for all but major earthquakes.

\section{PRELIMINARY SEISMIC DESIGN}

\subsection{Seismic Shear}

Initial design was based on eight dissipators (two at each support) with a total yield force equal to $5 \%$ of the superstructure weight, as suggested by Skinner and McVerry (3). A preliminary design sketch of a typical dissipator is shown in Fig. 2a, and the force-deflection hysteresis loop, based on information supplied by the P.E.L. is included in Fig. 2b. For preliminary design, the seismic shear at each pier was derived by setting the dissipator deflection at $76.2 \mathrm{~mm}$, corresponding to a maximum steel strain of $3 \%$, and summing the dissipator and elastomeric bearing shear forces at this displacement. It should be noted that the dissipators are capable of sustaining larger deflections at the expense of a reduced number of cycles before fatigue

\# pers. comm. R. I. Skinner. 
failure.

\subsection{Capacity Design}

The piers were designed using the following capacity design approach. Seismic shear derived in the previous section was adopted as a probable value. This shear was applied at the centre of gravity of the superstructure to generate a probable maximum base moment, and pier flexural reinforcement was based on this moment using a probable steel yield stress of $316 \mathrm{MPa}$ (1.15x nominal $\left.f_{y}\right)$, and a load factor of unity. The pier design shear force was derivea from pier overstrencth base moment, based on a steel stress of $344 \mathrm{MPa}$ (1.25x nominal $\left.f_{Y}\right)$, and a shear capacity reduction factor $\phi \underline{=} 0.85$ adopted. Pilecap and piles were designed using pier overstrength drive moment and dependable strength $(\phi=0.9$ for flexure, $\phi=0.85$ for shear).

The piers were initially sized by preliminary design as $2.0 \mathrm{~m}$ octagons, but following the computer dynamic analyses described in subsequent sections, were reduced in size to $1.8 \mathrm{~m}$ octagons. Final pier reinforcing is at the minimal $1 \%$

limit. Further reduction in pier size with a corresponding increase in reinforcing content was considered inappropriate on aesthetic grounds.

\section{COMPUTER ANALYSES}

\subsection{Computer Model}

Although both transverse and longitudinal analyses were performed, only the former will be discussed here in detail, as these were found to dominate design. Diaphragm action of the slab was assumed to be largely ineffective due to existing normal transverse flexural cracking, and additional torsional cracking induced by seismic response. Thus the internal piers were conservatively designed for the full contributory mass corresponding to one complete span. For a comparatively light heavily trafficked bridge such as the South Brighton Bridge it might be considered reasonable to incorporate some seismic live-load in the superstructure mass. view of the conservative nature of the assumption about deck diaphragm action, this was not felt to be necessary.

Fig. 3 represents the analytical model used to investigate transverse response. The superstructure and pier hammerhead masses have been distributed to nodes $3.75 \mathrm{~m}$ each side of the centreline to correctly simulate torsional mass inertia of the superstructure. Node numbering is included, and member numbers given in parenthesis adjacent to the appropriate member.

Member 1, representing the pier stem included a rigid-end block to represent the stiffening effect of the pier hammerhead and was given a moment of inertia appropriate to a cracked section just prior to yield. Node 1, at the base of the pier was fully fixed, as initial calculations showed the extent of foundation flexibility to be insignificant. The plastic hinge length was set at $0.70 \mathrm{~m}$ on the basis of equations in the Highway Bridge Design Brief $(2)$.

Because an estimate of probable response rather than worst feasible response was required, the yield moment of $10.4 \mathrm{MNm}$ was based on the specified concrete strength and a probable steel yield stress $15 \%$ higher than the specified minimum. Effects of moment enhancement due to concrete confinement were ignored, but hysteretic postyield behaviour was represented by a bi-linear moment-curvature loop with postyield stiffness set to $1 \%$ of the elastic stiffness to represent strain-hardening.

Properties for members 2 and 4 , and 6 , representing the pier hammerhead and deck/ diaphragm system respectively were based on uncracked response.

Nodes 3 and 5 were located at the centre of gravity of the pier hammerhead, while nodes 4 and 6 were located at the superstructure centre of gravity. As can be seen from Fig. 3 this resulted in members 3 and 5, representing the seismic isolation system, having an effective length of $2.12 \mathrm{~m}$. Two main variations in the properties of these members were investigated. In the first, each member ( 3 and 5 ) was given an axial stiffness equal to that of 6 Advanx Ml1-115-4 elastomeric bearings. The moment of inertia was adjusted so that transverse flexural deformations under a given shear loading would duplicate shear deformations of the actual bearings. These members were assumed to remain elastic. For the second system the axial stiffness was left unaltered, but the flexural stiffness of one cantilever dissipator was added to the transverse stiffness of each of members 3 and 5. The properties of the dissipator were based on the data presented in Fig. $2 \mathrm{~b}$.

Fig. 4 describes the bilinear hysteresis loop representing the combined behaviour of the damper plus 6 elastomeric bearings, drawn for a maximum displacement of $110 \mathrm{~mm}$. This is a typical level of peak response under a major earthquake. It will be noted that the stiffness of the post-yield portion of the loop exceeds $52 \%$ of the elastic stiffness, and that the loop appears to be rather thin. This contrasts with the typically fat hysteresis loops published for energy dissipation devices, including the steel cantilever, and results from the inclusion in Fig. 4 of the elastomeric bearings to give total response, rather than isolating the dissipator characteristics. In fact for this typical bridge, dissipator stiffness was almost identical to total bearing stiffness. Since the latter do not yield, they tend to dominate the response, as will be shown later.

For comparative purposes, analyses were also run with members 3 and 5 given effectively rigid properties to model monolithic pier/superstructure construction.

\subsection{Earthquake Records}

Two earthquake records exhibiting rather different characteristics were chosen. The first was the initial $15 \mathrm{sec}$. of the familiar El Centro $1940 \mathrm{~N}-\mathrm{S}$ record which is characterised by peak acceleration responses from elastic systems with periods in the $0.3-0.5$ sec. range. The second record was a preliminary digitization of the Bucharest $1977 \mathrm{~N}-\mathrm{S}$ record which excites unusually 
high response from elastic structures with natural periods in the $1.2-1.7$ sec. range. The peaks of the $2 \%$ damping acceleration response spectra of EI Centro and Bucharest are similar, but occur at different periods.

A course digitization of the Bucharest earthquake was used, resulting in a Nyquist period of about $0.4 \mathrm{sec}$. Since hand analyses indicated that all models investigated in this study would have much higher periods than this, inaccuracies due to the coarse digitization should not be significant.

\subsection{Computer Program}

Dynamic inelastic time-history analyses were carried out using a program 'TWODEE' developed by sharpe (5). A time-step of $0.005 \mathrm{sec}$. was adopted for all analyses, and damping was set at $5 \%$ critical for the first two modes.

\section{RESULTS}

The initial purpose of the dynamic analyses was to check the seismic response of the intended dissipator system, and to compare results with the bearing-only case. As it soon became apparent that the dissipators were not being particularly effective, a further set of analyses representing a monolithic pier/superstructure design were performed. These were only run for comparative purposes; the monolithic approach was not feasible because of the short pier stems.

\subsection{Pier Base Moments}

Comparisons of Pier base-moment time histories for El Centro and Bucharest responses are given in Figs. 5 and 6 . Under El Centro (Fig. 5) the monolithic design reaches yield on seven occasions, while the design incorporating dissipators and bearings has a peak response well below yield. However, the response of the design incorporating elastomeric bearings but excluding dissipators is also well below yield, and is in fact very similar to the response of the design including dissipators.

The Bucharest 77 response is rather different. In this case all three models are subjected to two yield excursions. Peak response occurs between 3 and 3.5 sec. with sufficient inelastic deformation to result in substantial strain-hardening for the two models incorporating bearings. Again there appears to be little to choose between the results for the designs with and without dissipators, but response of the monolithic design appears better, as the strain-hardening sustained by this model is clearly insignificant.

\subsection{Pier-Top Displacements}

Figs 7 and 8 compare time-histories with displacements at the centre of the pier hammerhead, that is, at a level below the bearings and dissipators. El Centro response (Fig. 7), as expected for elastically responding systems is qualitatively similar to the pier base-moment response, with the results of the two designs incorporating bearings being similar, and the improvement resulting from incorporation of the dissipators being relatively insignificant. It will be noted that the monolithic design is subjected to a modest plastic set of about $10 \mathrm{~mm}$

Displacements under Bucharest 1977 (Fig. 8) show that the two designs incorporating bearings are both subjected to a massive displacement pulse at the time corresponaing to peak moment response in Fig. 7 (i.e. at about 3.3 sec.) resulting in very substantial plastic set in the vicinity of 75-100 mm. The dissipators have had a moderate effect in reducing maximum displacement. By contrast, however, the monolithic construction has been comparatively unaffected by the earthquake, with displacements and plastic sets only a fraction of the values for the other two analyses.

\subsection{Final Design}

On the basis of the results presented in Figs 5 to 8 it was felt that the beneficial effects of the dissipators in reducing response were at best marginal, and rather uncertain. It is significant to note that, based on the El Centro response alone, possible savings in reinforcement costs of less than $\$ 500$ are only a fraction of the estimated installed cost of the dissipators of $\$ 10,000$. If response under the Bucharest record is considered, no savings in reinforcement are possible.

Smith has indicated ${ }^{(6)}$ that Christchurch is likely to be subjected to ground motion intensity equal to that of the El Centro 1940 record with a return period of between 100 and 250 years. Since the expected life of a bridge structure is within this time scale, it was decided to adopt El Centro as the 'design' earthquake, and utilise the results for El Centro analyses previously run as data for redesign of the piers. This enabled the pier diameter to be reduced to $1.8 \mathrm{~m}$, with a yield moment based on probable material strengths of $7.32 \mathrm{MNm}, 30 \%$ less than the value adopted for the initial design incorporating dissipators. It was considered prudent, as previously stated, to provide earthquake stops at each pier, and linkage bolts at the abutments as a second line of defence against superstructure displacements substantially larger than anticipated. The cost in providing this additional protection is significantly less than that of the dissipators.

It is pertinent to note that the design seismic shear adopted is equal to $9.3 \%$ of the superstructure weight (conservatively ignoring shear resisted by abutment bearing deformation). This is more than $50 \%$ higher than the value specified for $Z$ one $B, T=$ 1.42 sec, by the Highway Bridge Design Brief(2). In fact, in the final analysis, Dead+Live Load governed pier design.

Dynamic analyses were run for the revised pier with the superstructure supported on elastomeric bearings without dissipators. Final design was carried out on the basis of the results of these analyses using capacity design as outlined in section 2.2. Detailing for ductility was in accordance with the provisions of the Highway Bridge Design Brief $(2)$.

Salient results for the dynamic analyses are presented in Table 1 which includes corresponding values from the previous three 
cases for comparison with each other and with the final design. It will be noted that under El Centro attack response of the final design is elastic and very similar to the $2.0 \mathrm{~m}$ dia. case. Under Bucharest attack behaviour is better than for the $2.0 \mathrm{~m}$ dia. case. Base moments and shears (and hence forces to the pile group) are reduced without a corresponding increase to curvature ductility. Although a high curvature ductility, corresponding to a structure ductility of about 9 is sustained, cummulative structure ductility (total over all yield excursions) is less than 14. This compares with a value of about 48 implied by four yield cycles to a ductility of 6 required by the Highway Bridge Design Brief. Consequently failure is not expected. Maximum bearing displacement at $145 \mathrm{~mm}$ is large, but less than for the $2.0 \mathrm{~m}$ pier, with or without dampers, and final plastic set at $79 \mathrm{~mm}$ compares closely with the $2.0 \mathrm{~m}$ pier with dissipators.

\section{DISCUSSION OF RESULTS}

The authors were somewhat surprised to find how little effect the design dissipators had on response. They conclude that the reason lies in the fact that previous relevant papers have compared response of monolithic systems with the corresponding systems incorporating bearings and dissipators. It will have been noted on the basis of results presented in this paper that the difference between such cases can be large, though not in all cases beneficial. As far as the authors are aware, the separate influence of the elastomeric bearings and dissipators has not previously been isolated in analyses.

It is clear from these results that the elastomeric bearings have a greater influence on response than the dissipators. This would be expected after examination of the bilinear load-deflection hysteresis loop presented in Fig. 4. The loop is comparatively slender and clearly dominated by the stiffness of the bearings, as noted earlier. Behaviour is similar to an elastic hysteresis loop with equivalent viscous damping of about 5-7\%.

The fundamental action of the bearings is to increase the natural period to somewhere in the range $1.3-2.0 \mathrm{sec}$. for other than long bridges. The actual value will depend mainly on the ratio.

\section{superstructure dead load}

Lateral bearing stiffness

However lateral bearing stiffness is roughly proportional to vertical stiffness, with the range of the ratio being comparatively small for commercially available bearings. Vertical stiffness is related to vertical load carrying capacity which will be chosen on the basis of maximum Dead Load plus Live Load reaction. It can thus be shown that the natural period $\mathrm{T}$ will be roughly proportional to

$T \propto \sqrt{\frac{\text { D.L. reaction }}{\text { D.L. }+ \text { L.L. reaction. }}}$,

since Live Load is commonly ignored in seismic analysis. The ratio $\mathrm{DL} /(\mathrm{DL}+\mathrm{LL})$ will vary in the range 0.4 to 1.0 , depending on the span length, resulting in a comparative uniformity in the natural period.
Incorporation of dissipators increases the structural damping somewhat, but has little additional effect. Clearly the effect of elastomeric bearings (and dissipators if incorporated) will be beneficial only if the increase in natural period is accompanied by a reduction in the acceleration response spectra. This depends on the characteristics of the particular earthquake, as illustrated by the difference in results obtained in this investigation for $\mathrm{El}$ Centro and Bucharest. The reason is plain on examination of Fig. 9, which shows the shift in natural period of the system on incorporation of bearings, in relation to simplified response spectra (2\% damping) of El Centro and Bucharest. For El Centro, the shift in period results in a substantial drop in response, while for Bucharest, it moves the structure into the region of maximum response.

\section{CONCLUSIONS}

Limited time-history analyses on an actual bridge design revealed the following characteristics.

1. Design to avoid pier yield by use of steel-cantilever dissipators resulted in higher pier base moment requirement than would be obtained from design to the Highway Bridge Design Brief. Adoption of this design would result in a more costly substructure, particularly from a requirement for extra piles.

2. Insufficient reduction in response was obtained from incorporation of the dissipators to warrant their inclusion.

3. For seismic isolation of this bridge using elastomeric bearings and dissipators, behaviour is dictated by the bearings. The dissipators are comparatively ineffective, providing a small additional equivalent viscous damping, and result in a reduction in peak responses of between $0-30 \%$.

General conclusions that can be made on the basis of this study are :-

4. Superstructures supported by commercially available elastomeric bearings will have natural periods greater than 1.3 secs.

5. Whether or not inclusion of bearings (and dissipators) will tend to 'isolate' the bridge against seismic attack will depend on the response spectra of the specific earthquake. Under earthquakes with similar characteristics to El Centro 1940, this will invariably be the case. However, there are many more recent earthquakes (Bucharest, Parkfield) where response will not be improved, and may in fact be affected detrimentally. Clearly information on characteristics of earthquakes for New zealand sites is urgently needed.

6. Although there will undoubtedly be special cases where the use of steel or lead dissipators is warranted, for the typical, standard bridge it appears that benefits will not warrant the extra costs involved in manufacture, installation and maintenance.

\section{ACKNOWLEDGEMENTS}

Acknowledgement is made of the 
permission of the Christchurch City Council Deputy General Manager, and the City Engineer, to publish this paper.

\section{REFERENCES}

1. Stockwell, M. J., "Durham St. Overbridge, Christchurch". N.Z. Engineering, Vol. 30, No. 7, 1975 pp 200-206.

2. M.W.D., "Highway Bridge Design Brief", Issue C, 1973. $51 \mathrm{pp}$.

3. Skinner, R. I., McVerry, G. H., "BaseIsolation for Increased Earthquake Resistance of Buildings". Bull. N.Z. National Soc. for Earthquake Engineering, Vol. 8, No. 2, June 1975 pp 93-101.

4. Blakeley, R. W. G., "Prestressed Concrete Bridges Incorporating Mechanical Energy Dissipating Devices for Earthquake Resistance", M.W.D. Civil Div. Report, to be presented to F.I.P. Congress, London, May 1978.

5. Sharpe, R. D., "The Seismic Response of Inelastic Structures", Ph.D Thesis, Dept. of Civil Eng., Univ. Canterbury, Res. Rep. No. 74-13, Nov. 1974, 126pp.

6. Smith, W. D., "Statistical Estimates of the Likelihood of Earthquake Shaking Throughout New Zealand", Bull. N.z. National Soc. for Earthquake Engineering, Vol. 9, No. 4, Dec. 1976, pp 213-221.

Paper received I May, 1978. 
TABLE I

RESULTS OF TIME-HISTORY ANALYSES OF TRANSVERSE SEISMIC RESPONSE

\begin{tabular}{|c|c|c|c|c|c|c|c|c|}
\hline \multirow[b]{3}{*}{$\begin{array}{l}\text { Natural period } \\
(\text { secs.) }\end{array}$} & \multicolumn{4}{|c|}{ EL CENTRO $1940 \mathrm{~N}-\mathrm{S}$ (15 sec.) } & \multicolumn{4}{|c|}{ BUCHAREST $1977 \mathrm{~N}-\mathrm{S}$ (12 sec.) } \\
\hline & $\begin{array}{l}2.0 m \text { dia. } \\
\text { monolithic }\end{array}$ & $\begin{array}{l}2.0 \mathrm{~m} \text { dia. } \\
\text { bear.only }\end{array}$ & $\begin{array}{l}2.0 \mathrm{~m} \text { dia. } \\
\text { bear.+ } \\
\text { dissipators }\end{array}$ & $\begin{array}{l}1.8 \mathrm{~m} \text { dia.* } \\
\text { bear. only }\end{array}$ & $\begin{array}{l}2.0 \mathrm{~m} \text { dia. } \\
\text { monolithic }\end{array}$ & $\begin{array}{l}\text { 2.0m dia. } \\
\text { bear.only }\end{array}$ & $\begin{array}{l}2.0 \mathrm{~m} \text { dia. } \\
\text { bear.+ } \\
\text { dissipators }\end{array}$ & $\begin{array}{l}\text { 1. } 8 \mathrm{~m} \text { dia. * } \\
\text { bear.only }\end{array}$ \\
\hline & 0.68 & 1.39 & 1.06 & 1.42 & 0.68 & 1.39 & 1.06 & 1.42 \\
\hline $\begin{array}{l}\text { Maximum Deck } \\
\text { Displacement }(\mathrm{mm})\end{array}$ & 38.1 & 106.4 & 74.2 & 108.4 & 32.2 & 287.9 & 229.7 & 238.8 \\
\hline $\begin{array}{l}\text { Max. Bearing } \\
\text { Displacement (mm) }\end{array}$ & $N \cdot A$. & 96.2 & 64.8 & 96.1 & N.A. & 220.0 & 175.0 & 145.0 \\
\hline $\begin{array}{l}\text { Max. Pier } \\
\text { Displacement }(4.73 \mathrm{~m})\end{array}$ & 24.1 & 10.2 & 9.4 & 12.3 & 20.0 & 138.6 & 99.4 & 119.3 \\
\hline $\begin{array}{l}\text { Pier Yield } \\
\text { Moment (MNm) }\end{array}$ & 10.4 & 10.4 & 10.4 & 7.32 & 10.4 & 10.4 & 10.4 & 7.32 \\
\hline $\begin{array}{l}\text { Max. Pier } \\
\text { Moment (MNm) }\end{array}$ & 10.6 & 7.32 & 6.45 & 7.09 & 10.5 & 12.6 & 11.9 & 8.82 \\
\hline $\begin{array}{l}\text { Max. Pier } \\
\text { Shear (KN) }\end{array}$ & 1775 & 1015 & 781 & 989 & 1627 & 2046 & 2069 & 1451 \\
\hline $\begin{array}{l}\text { Max. Pier Duct } \\
\text { (Curvature) }\end{array}$ & 2.8 & Nil & Nil & Nil & 2.0 & 22.0 & 15.3 & 21.5 \\
\hline $\begin{array}{l}\text { No. damper } \\
\text { yields }\end{array}$ & N.A. & N.A. & 22 & N.A. & N.A. & $N \cdot A$. & 13 & N.A. \\
\hline $\begin{array}{l}\text { No. pier } \\
\text { yields }\end{array}$ & 7 & $\mathrm{Nil}$ & $\mathrm{NiI}$ & Nil & 2 & 2 & 2 & 5 \\
\hline $\begin{array}{l}\text { Final Plastic } \\
\text { set }(\mathrm{mm})\end{array}$ & 10.7 & Nil & Nil & $\mathrm{Nil}$ & 7.7 & 105 & 76 & 79 \\
\hline
\end{tabular}

* Final design choice 
116
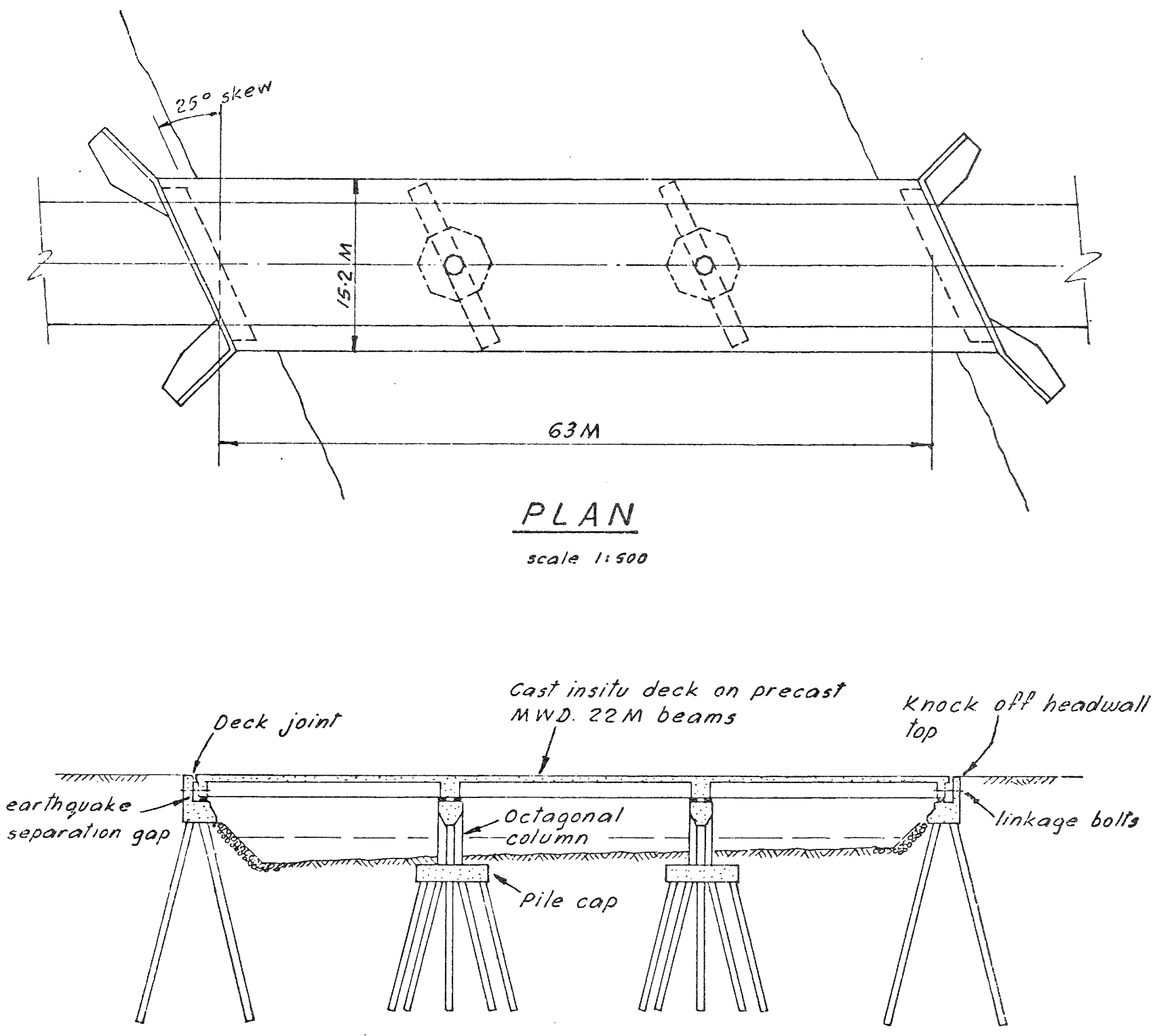

$\frac{\text { LONGITUDINAL SECTION }}{\text { scale } 1: 500}$

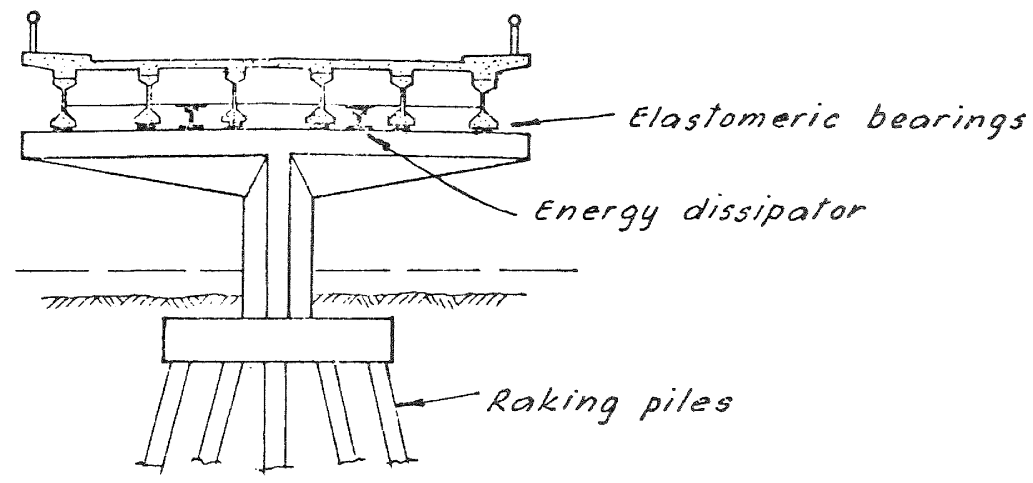

$\frac{\text { CROSS SECTION }}{\text { scale } 1: 250}$

FIGURE 1: BRIDGE DETAILS 


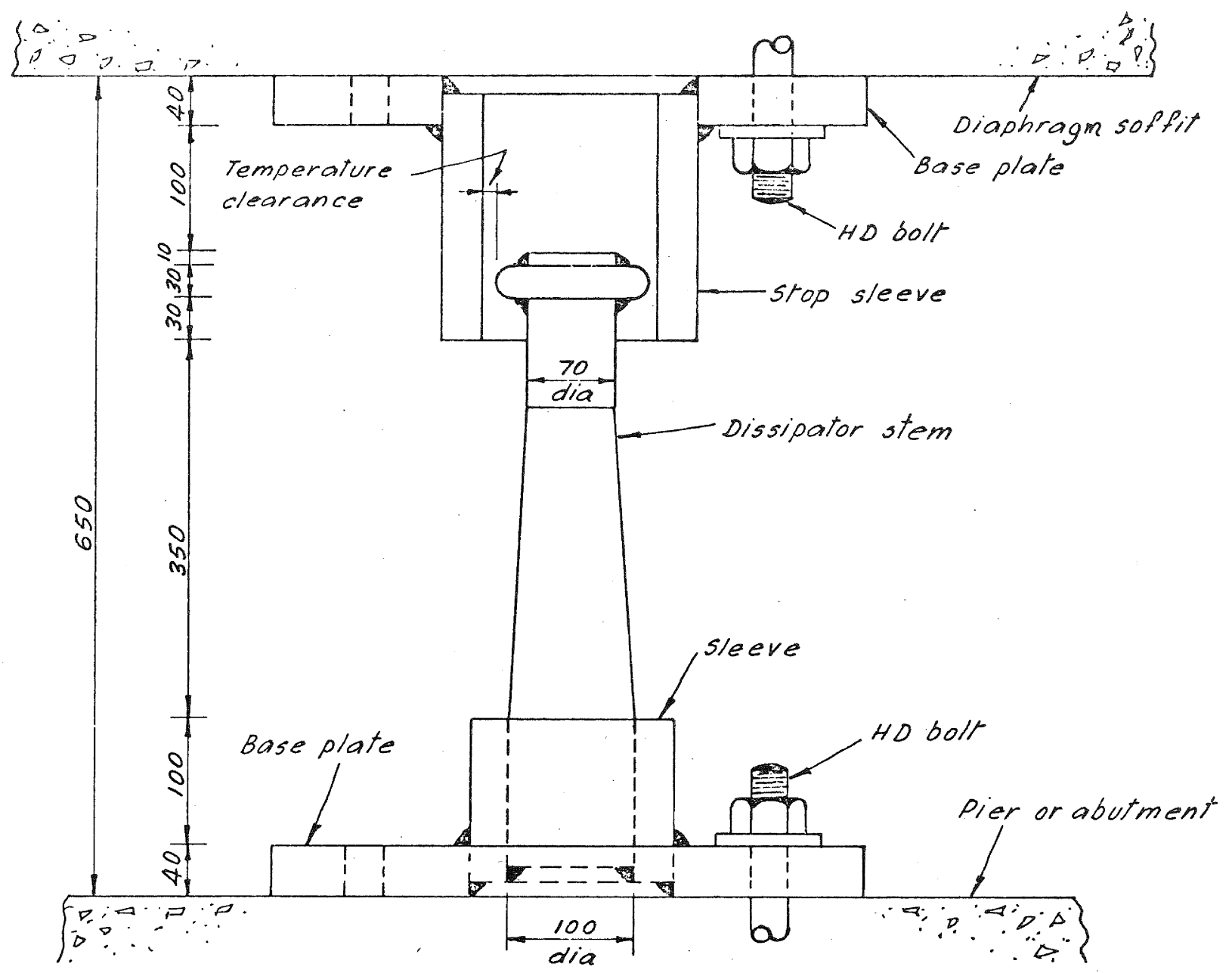

(a) DETAILS OF DISSIPATOR

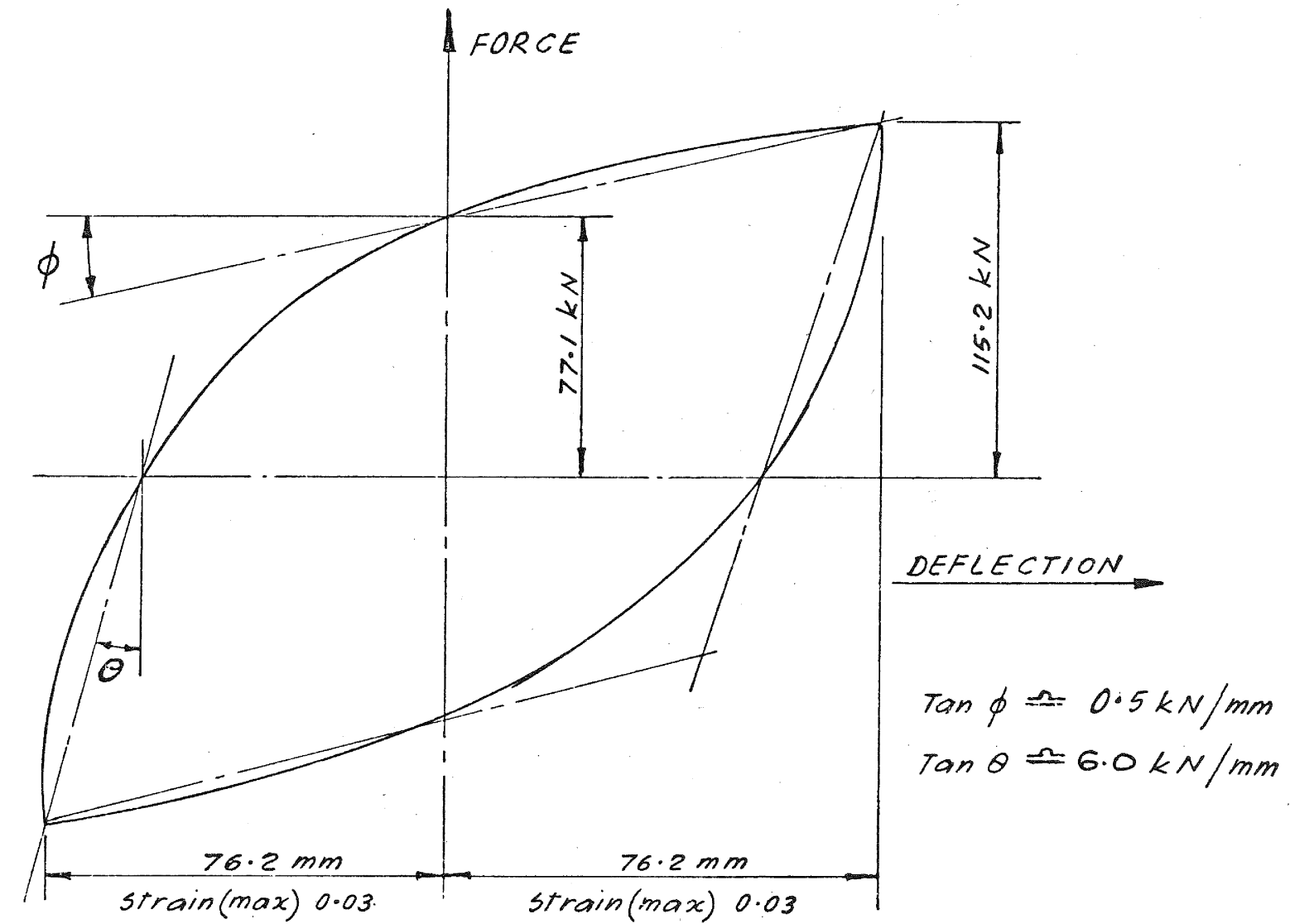

(b) FORCE-DEFLECTION HYSTERESIS LOOP

FIGURE 2: STEEL CANTILEVER DISSIPATOR 


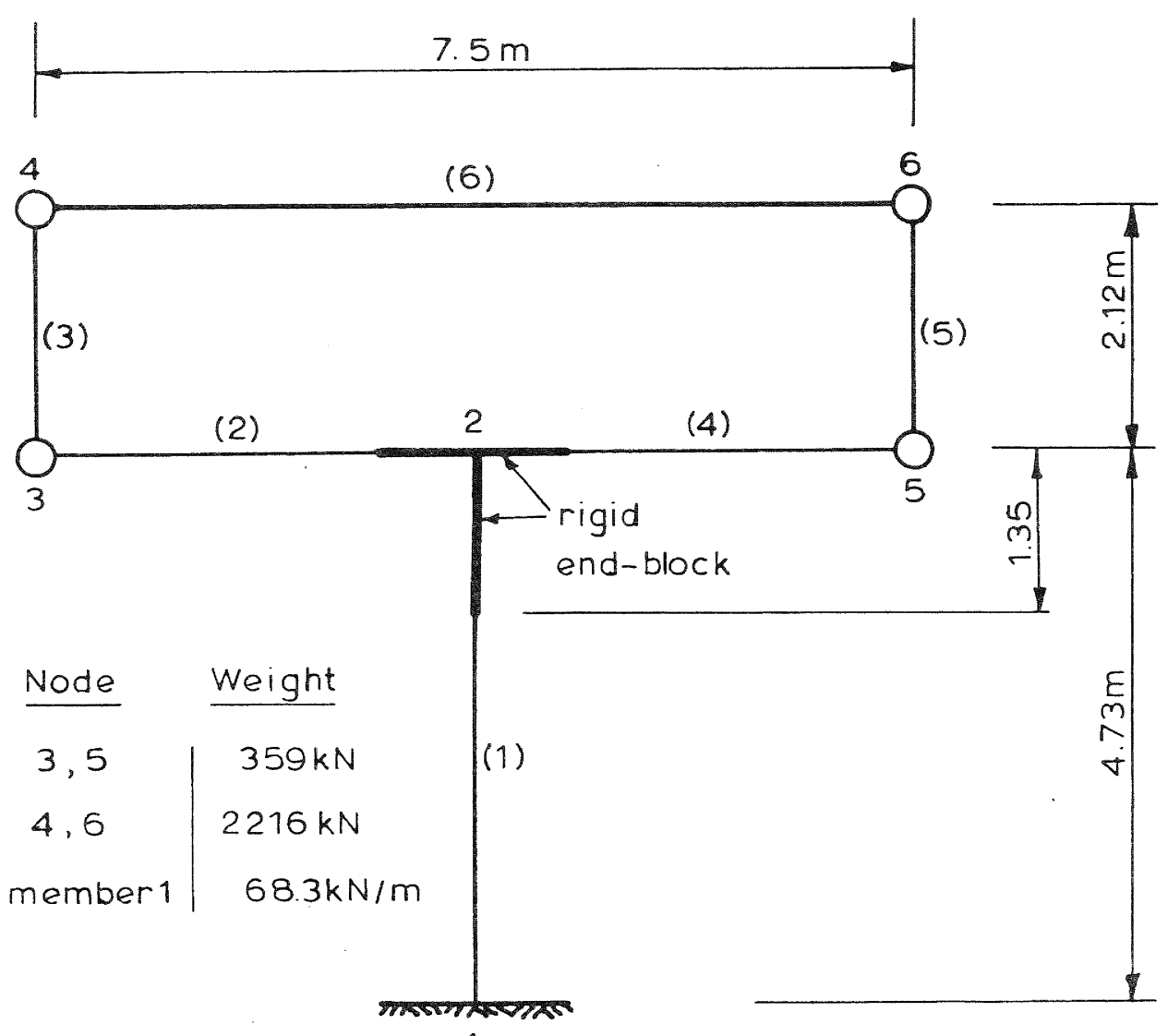

1

FIGURE 3: COMPUTER MODEL - TRANSVERSE

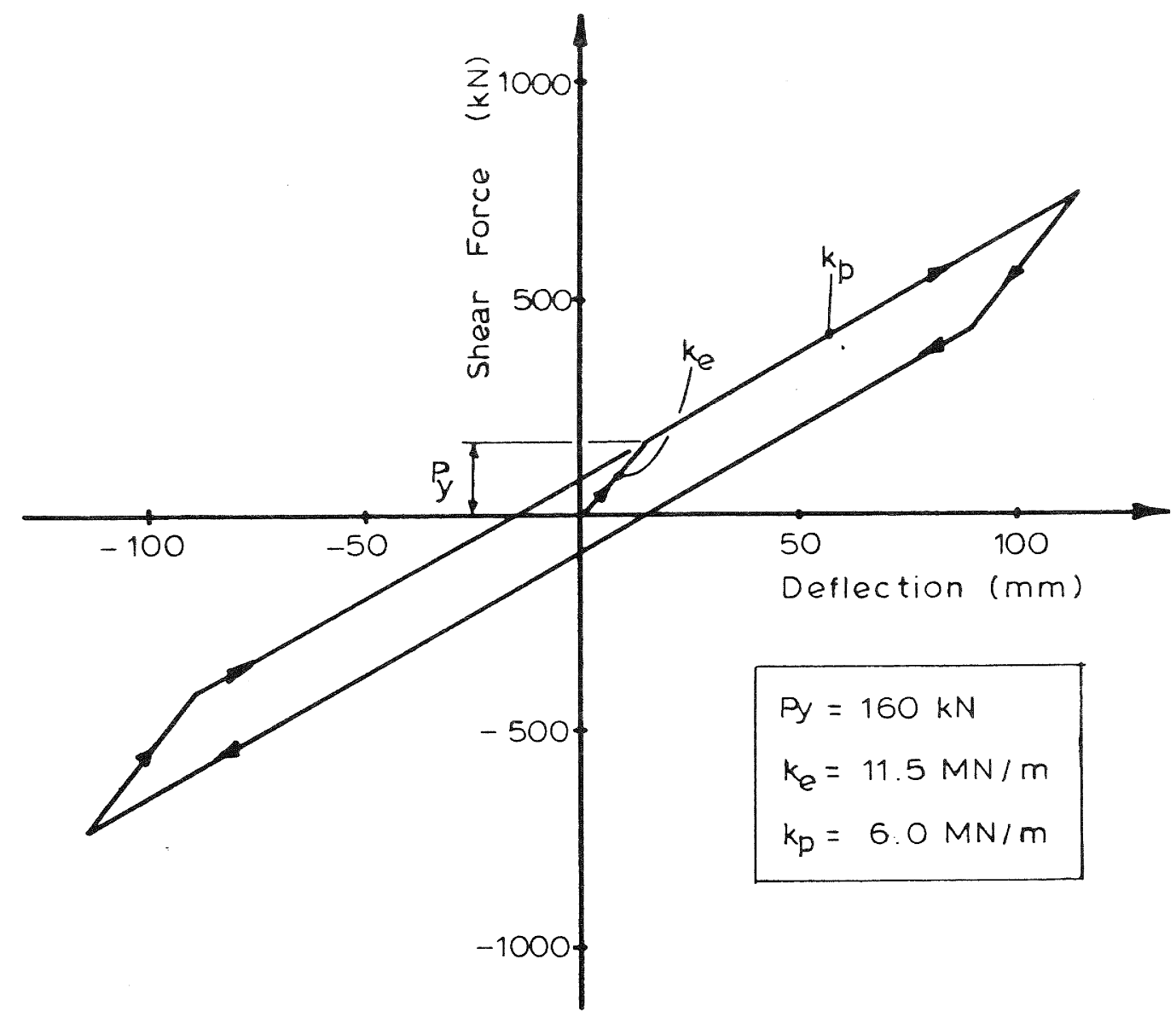

FIGURE 4: BEARINGS + DAMPERS - HYSTERESIS 


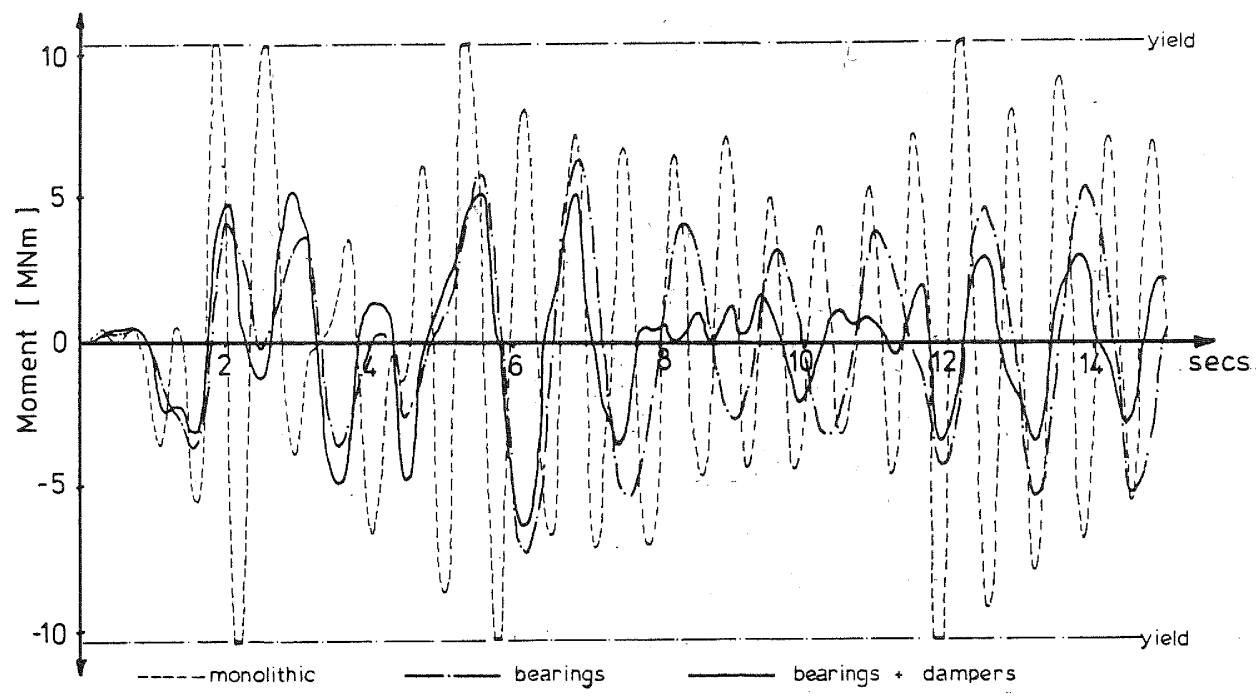

FIGURE 5: PIER BASE-MOMENTS, EL CENTRO 1940 N-S

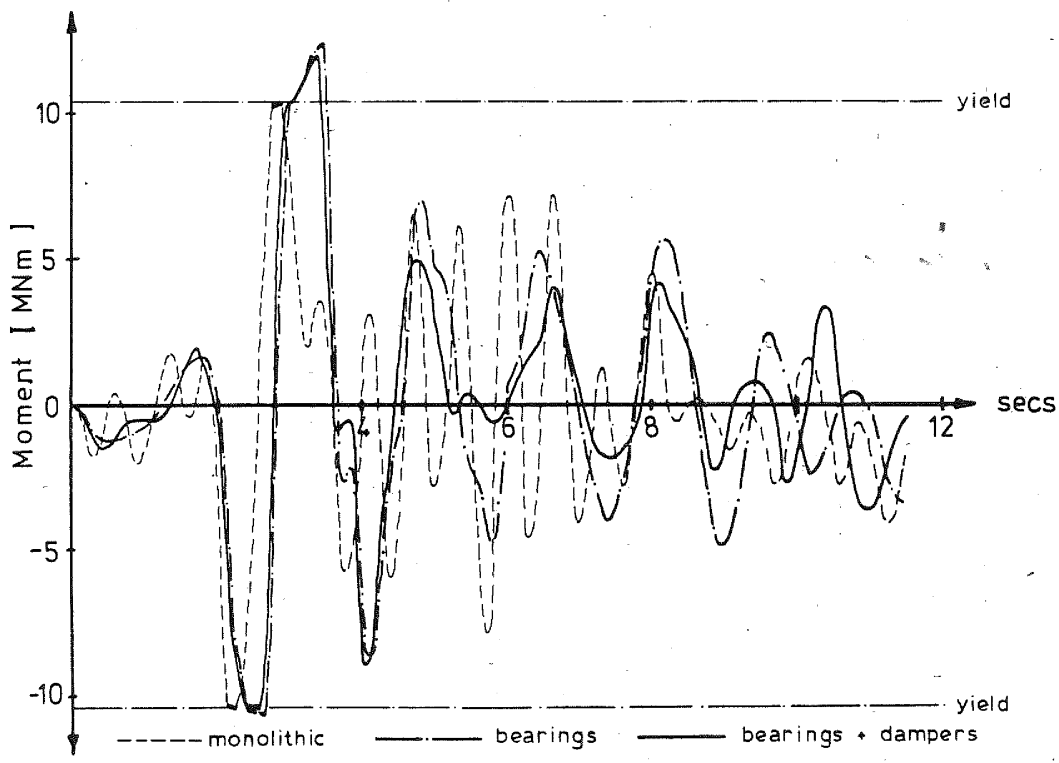

FIGURE 6: PIER BASE-MOMENTS, BUCHAREST 1977

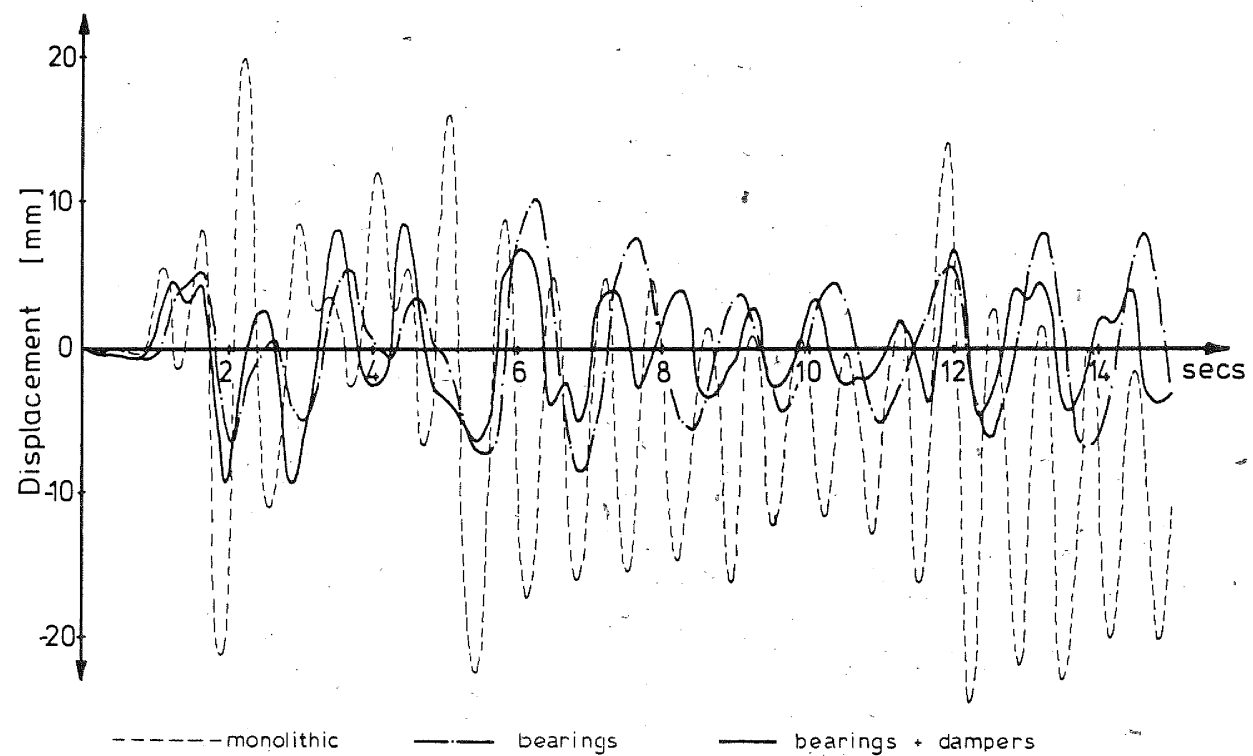

FIGURE 7: PIER DISPLACEMENT $(4.73 \mathrm{~m})$ EL CENTRO $1940 \mathrm{~N}$-S 


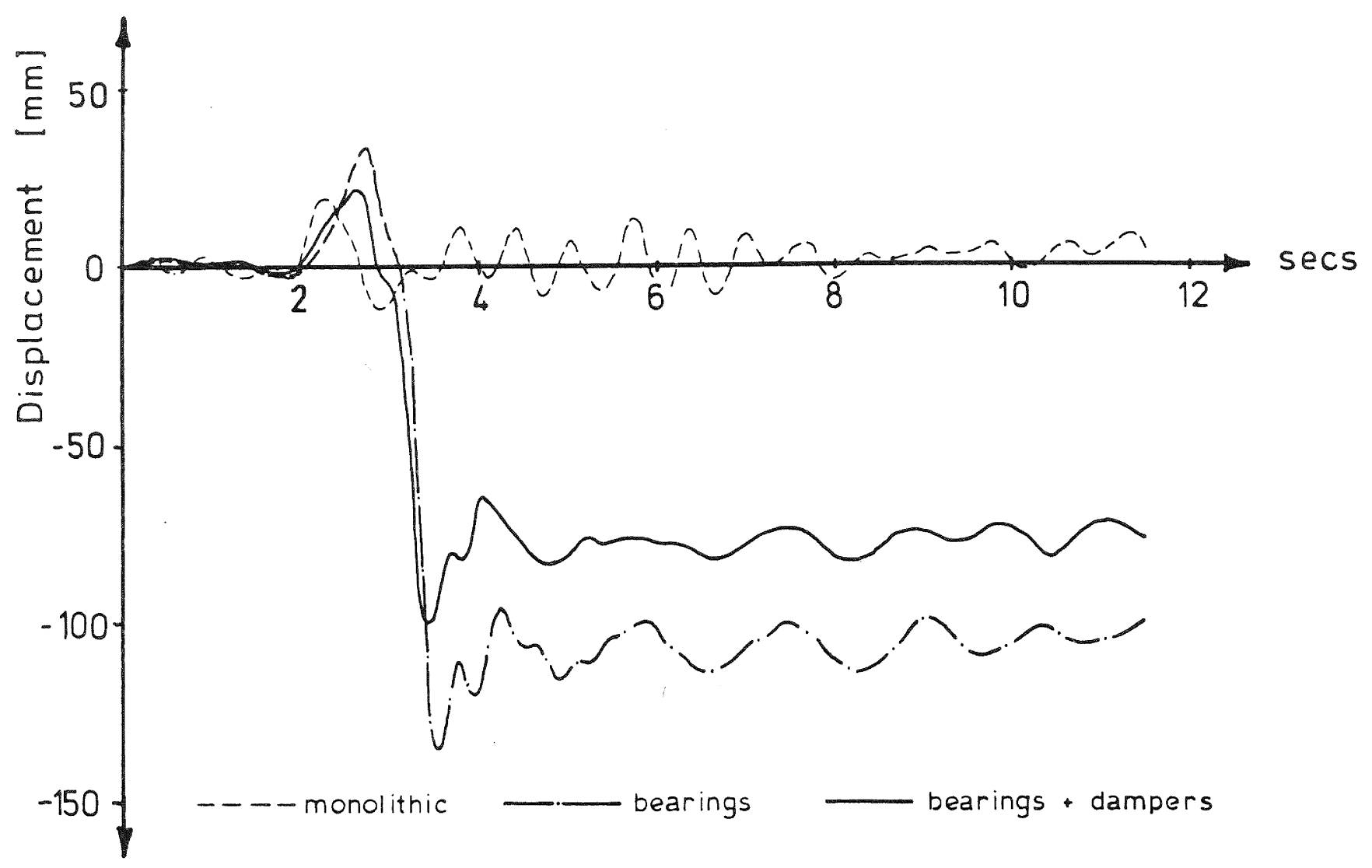

FIGURE 8: PIER DISPLACEMENT (4.73m) BUCHAREST 1977

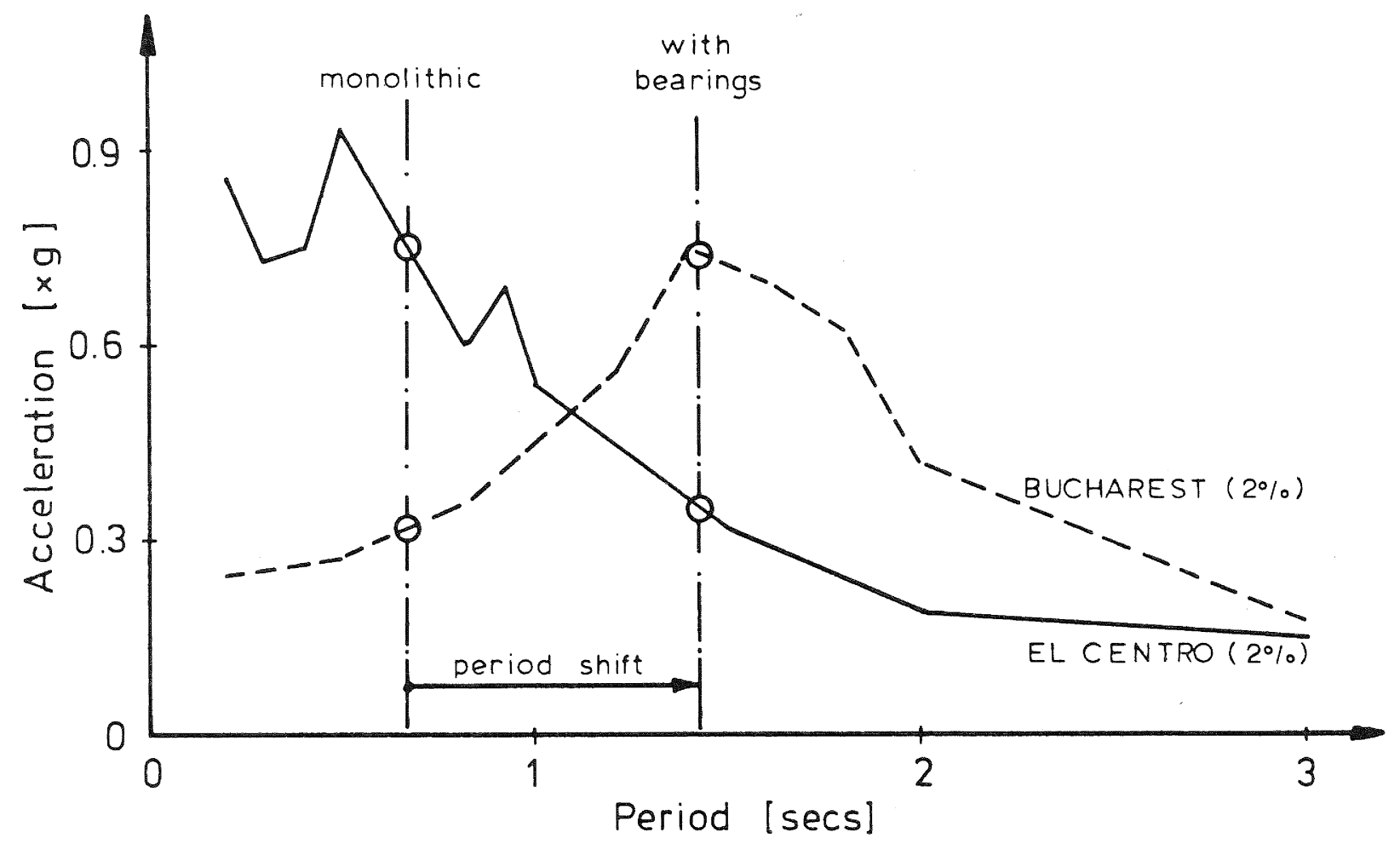

FIGURE 9: RELATIONSHIP BETWEEN PERIOD SHIFT AND RESPONSE SPECTRA 